1 Technical Note

\title{
Experimental Investigation on Loading-Relaxation Behaviors of Shear-Zone Soil
}

\author{
Deshan Cui ${ }^{1}$; Shun Wang ${ }^{2}$; Qiong Chen ${ }^{3}$; and Wei Wu ${ }^{4}$
}

\begin{abstract}
This paper presents an experimental investigation of the loading-relaxation behaviors of reconstituted shear-zone soils through drained triaxial tests. A multistage loading-relaxation approach is adopted to perform this test. The test aims to study two main issues: the influence of relaxation on the mechanical response during reloading; and the influence of strain rates, loading increments, and the relaxation time on the relaxation characteristics. The test results indicate that the stress-relaxation behavior of shear-zone soil is dependent on the stress and strain levels. The loading patterns prior to the stress-relaxation process affect mainly the viscoelastic behavior of the soil and subsequently influence the initial relaxation behavior. Moreover, a reloading after a stress-relaxation process gives rise to a higher deviatoric stress owing to the viscoplastic hardening. It is further shown that the loading-relaxation behaviors can be interpreted by the viscoplastic theory. DOI: 10.1061/(ASCE)GM.1943-5622.0001949. (C) 2021 American Society of Civil Engineers.
\end{abstract}

Author keywords: Huangtupo; Stress relaxation; Shear-zone soil; Triaxial compression test; Strain rate; Viscous behavior.

\section{Introduction}

Most reactivated slow-moving landslides in the Three Gorges Reservoir (TGR) area of China are characterized by preexisting shear zones (Miao et al. 2014; Wang et al. 2018b). The large deformation within the shear zones usually contributes to the majority of the whole landslide motion owing to the viscous behavior of the shear-zone soils. In general, the concept of viscous behaviors consists of three aspects, namely, rate dependence, creep, and stress relaxation (Feda 1992; Liingaard et al. 2004; Augustesen et al. 2004). Rate dependence and creep deformation can be widely observed in slow-moving landslides. It is reported that when affected by seasonal rainfall and periodic changes in water level, most slow-moving landslides exhibit a creep deformation characterized by a stepwise trend (Wang et al. 2018b). The change in strain rate in the shear zones could, in turn, affect the mobilized shear resistance of the shear-zone material and consequently influence the creep deformation of the landslide (Hu et al. 2018). Owing to the significance of this property, a series of works have been carried out to investigate the rate dependence (e.g., Scaringi et al. 2017; Hu et al. 2018) and creep properties (e.g., Li et al. 2017; Tan et al. 2018; Wang et al. 2018b, 2018c, 2020) of shear-zone soils taken from slow-moving landslides in the TGR. Compared with the tests on rate dependence and creep to date, there is insufficient experimental data for quantifying the stress-relaxation behavior of shear-zone materials. For the comprehensive investigation of the viscous

\footnotetext{
${ }^{1}$ Associated Professor, School of Engineering, China Univ. of Geosciences, Wu Han, 430074, PR China.

${ }^{2}$ Postdoc Research Fellow, Institut für Geotechnik, Univ. für Bodenkultur Wien, Feistmantelstrasse 4, A-1180 Vienna, Austria (corresponding author). Email: shun.wang@boku.ac.at

${ }^{3}$ Lecturer, School of Engineering, China Univ. of Geosciences, Wu Han 430074, PR China.

${ }^{4}$ Professor, Institut für Geotechnik, Univ. für Bodenkultur Wien, Feistmantelstrasse 4, A-1180 Vienna, Austria.

Note. This manuscript was submitted on July 15, 2020; approved on October 21, 2020No Epub Date. Discussion period open until 0, 0 ; separate discussions must be submitted for individual papers. This technical note is part of the International Journal of Geomechanics, (C) ASCE, ISSN 1532-3641.
}

behavior of the shear-zone soil, performing stress-relaxation tests under various stress paths is indispensable.

Conventional relaxation tests were mainly conducted in the undrained condition to obtain a pure relaxation process with constant strain. This situation, however, is unlikely to occur in a slowmoving reactivated landslide. Instead, while undergoing creep deformation, the shear-zone material in the landslide may experience relaxation processes if the shear zone is subjected to massive exposure, e.g., excavation near the shear zone (Wang et al. 2018b) or toe cutting owing to construction on the landslide area (Deng et al. 2016; Troncone et al. 2014). In these cases, a complex stress state is imposed on the shear-zone material and loading-relaxation coupling is likely to occur. There are several reports on the loadingrelaxation coupling effect for reconstituted clay in odometer tests (Bagheri et al. 2019) and triaxial tests (Wang et al. 2017). In these tests, the loading-relaxation coupling effects significantly influence the viscous behavior of the tested materials. For example, the rate and magnitude of the relaxed stresses increase with the increase in the prerelaxation strain and stress levels, and strain rates (Bagheri et al. 2019). Likewise, a stress-relaxation process is bound to affect the subsequent reloading behavior in a multistage loading-relaxation process. However, there is a lack of relevant research on shear-zone soils. Therefore, how the stress relaxation and loading influence each other in the shear-zone soils remains unknown. To this end, stress-relaxation tests combined with loading are anticipated to be carried out to fill the research gap of timedependent properties of shear-zone soils.

This paper presents the results of multistaged compressionrelaxation tests on a shear-zone soil taken from a reactivated slowmoving landslide in the TGR area. The coupled effects of loading patterns and relaxation behavior are investigated with two main issues: (1) the influence of relaxation on mechanical response of reloading; and (2) the dependence of relaxation properties on loading patterns, including prerelaxation strain rates, strain levels, and loading increments. The mechanism of the loading-relaxation coupling effect is discussed with the help of viscoplastic theory. The test results provide insights and data for the development of constitutive models for modeling the viscous behaviors of shear-zone materials under complex loading conditions. 


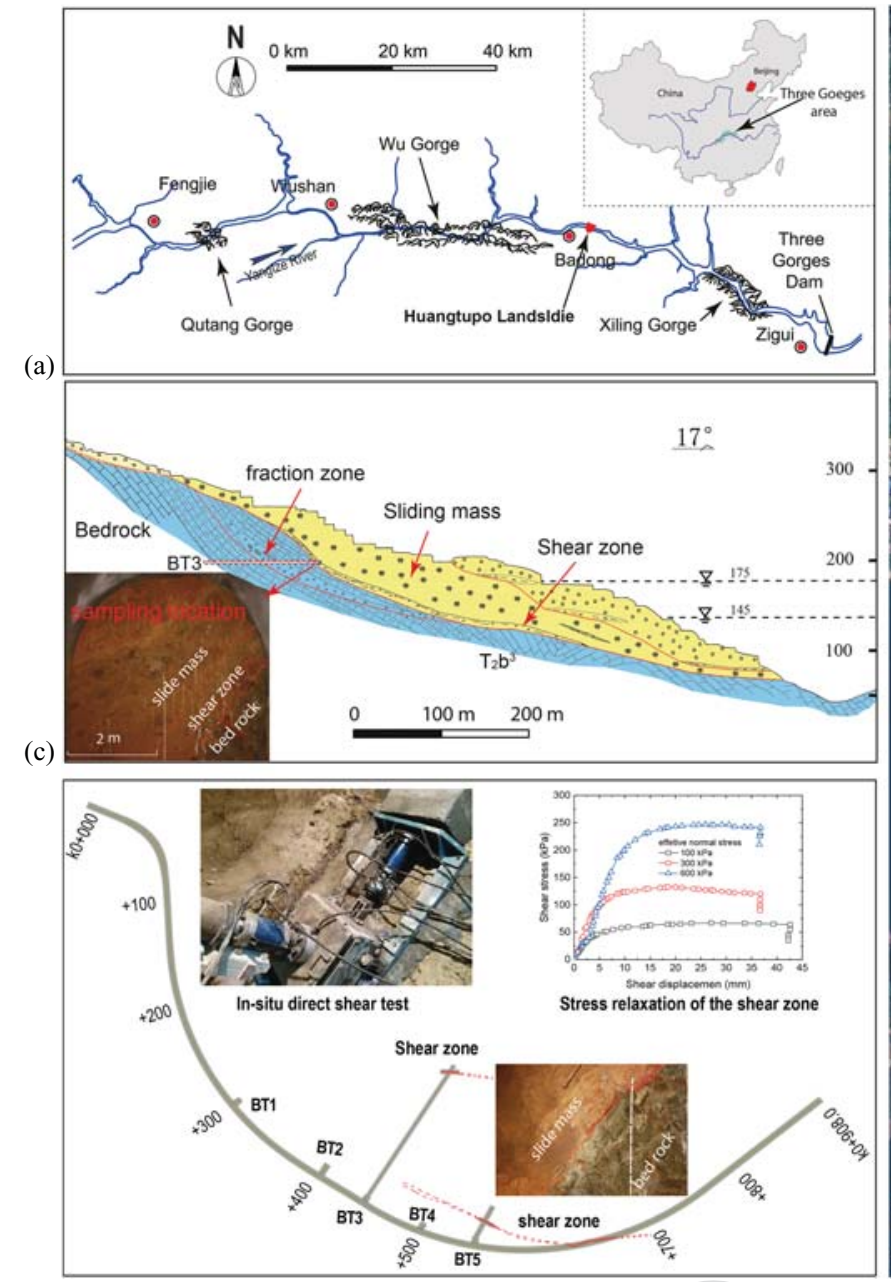

(d)

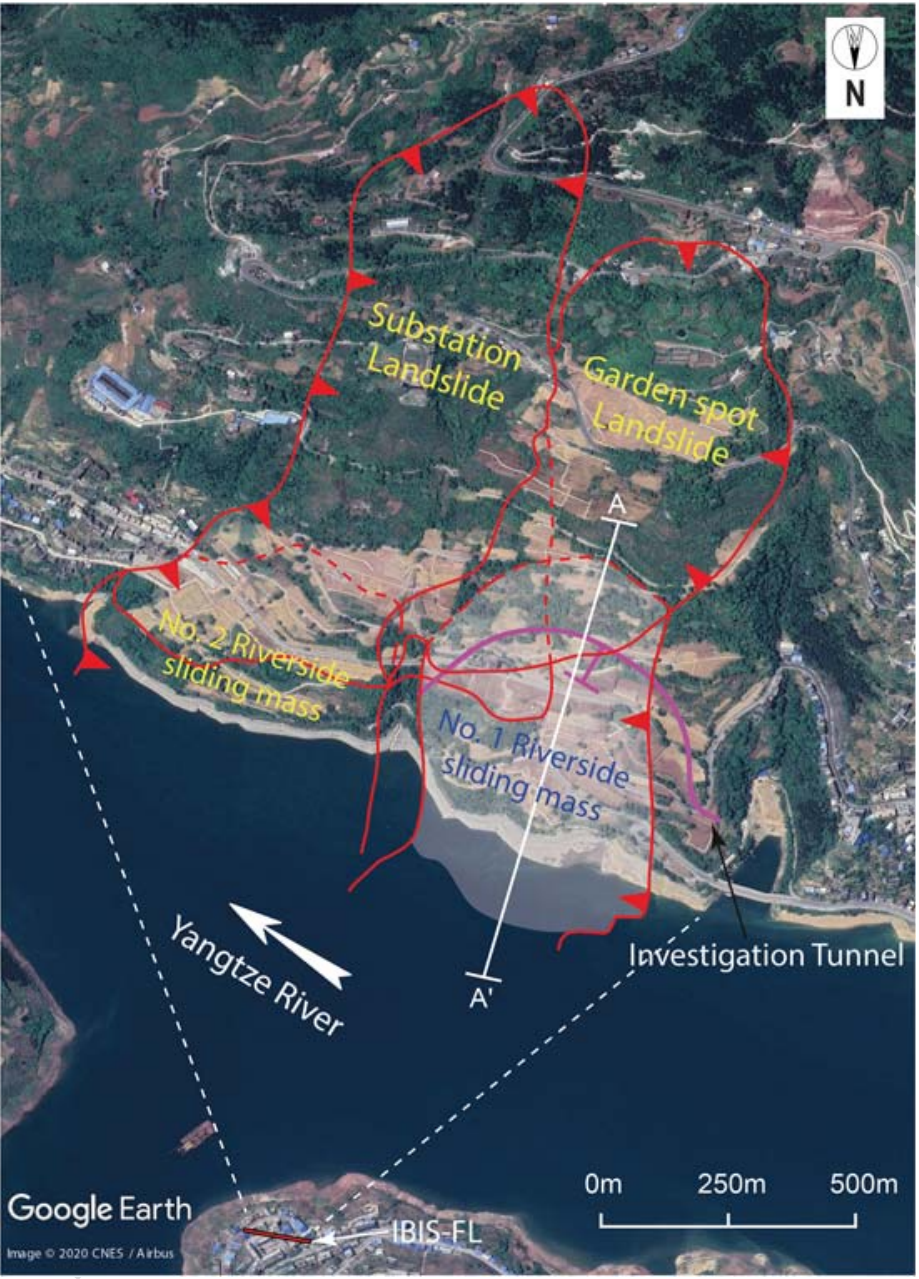

(b)

F1:1 Fig. 1. (a) Location; (b) plan view of the Huangtupo landslide with the investigation tunnel (base image from Google Earth 2020); (c) profile section

F1:2 $A-A^{\prime}$ of No. 1 Riverside sliding mass showing the sampling location; and (d) the investigation tunnel and observed stress relaxation during in situ direct shear tests. [Adapted (a) and (c-d) from Wang et al. 2020; image (c) Google Earth Image C 2020 CNES/Airbus.]

\section{Background}

The Huangtupo landslide, located in Badong County, Hubei Province, China (Fig. 1), is one of the largest $\left(69.34 \times 10^{6} \mathrm{~m}^{3}\right)$ and the most complex landslides in the TGR (Deng et al. 2000; Tang et al. 2019). Four different sliding masses, with separate shear zones, were detected in the landslide (Wang et al. 2014, 2016, 2018a). The large size and complex structure of Huangtupo landslide make it an ideal study object to better understand the mechanisms of similar slides in this area. In 2012, the Badong experimental station, including an intensive monitoring network and an investigation tunnel with five adits, was established by the Three Gorges Research Centre for Geohazards. The adits exposed several shear zones of this landslide for scientific experiments, such as in situ triaxial creep and direct shear tests (Wang et al. 2020; Tan et al. 2018).

It is noteworthy that the shear zones in the investigation tunnel will be exposed to the air for a very long time owing to the timeconsuming in situ mechanical tests. Without a lining support, stress redistribution will take place in the soil, and the exposed shear zone will move into the tunnel, leading to considerable stress relaxation in the shear zone. Moreover, the stress-relaxation phenomenon was also observed in in situ direct shear test. As shown in Fig. 1(d), for example, a significant stress relaxation occurred at the end of the in situ direct shear test when the shear displacement ceased. This large amount of stress relaxation was ascribed to the accumulation of structural defeat over time in the soil under the sustained strain. The stress was anticipated to be decreasing with time. However, further relaxation was not measured in the in situ test. According to the rheology theory of stress relaxation, the stress may decrease continuously within a relatively long period. The stress state and the observed stress relaxation in the shear zone bring about the necessity of performing triaxial relaxation tests to investigate the viscous behavior of the shear-zone material.

\section{Multistaged Compression-Relaxation Tests}

\section{Test Material and Specimen Preparation}

Some intact samples were taken from the shear zone exposed in the testing tunnel of the Badong field test site. The image in Fig. 1(c) shows the site for the soil sampling. Theses intact samples were used to obtain the basic physical characteristics of the shear zone, such as the mean natural water content $(w=14.23 \%)$, the mean bulk density $\left(\rho=2.25 \mathrm{~g} / \mathrm{cm}^{3}\right)$, and the mean plasticity index $\left(I_{p}=18.76\right)$. According to the grain size analyses shown in Fig. 2(a), the shear-zone soil typically comprises fine-grained soil (silt and clay) with a significant fraction of coarse-grained 
particles, constituting approximately $20-50 \mathrm{wt} . \%$ (wt. denotes mass fraction) of the material. The argillaceous particle content is 50 and $80 \mathrm{wt} . \%$. The fine-grained portion can be classified as silty clay with low to medium plasticity and silt-clay mixtures of low plasticity [see Fig. 2(b)].

The material in the shear zone is characterized as gravelly soil with inhomogeneously embedded coarse particles. It is reported that the inhomogeneity of the shear-zone soils has a significant influence on their viscous behaviors (Wen and Jiang 2017). Moreover, previous experiments with intact shear-zone soil of this
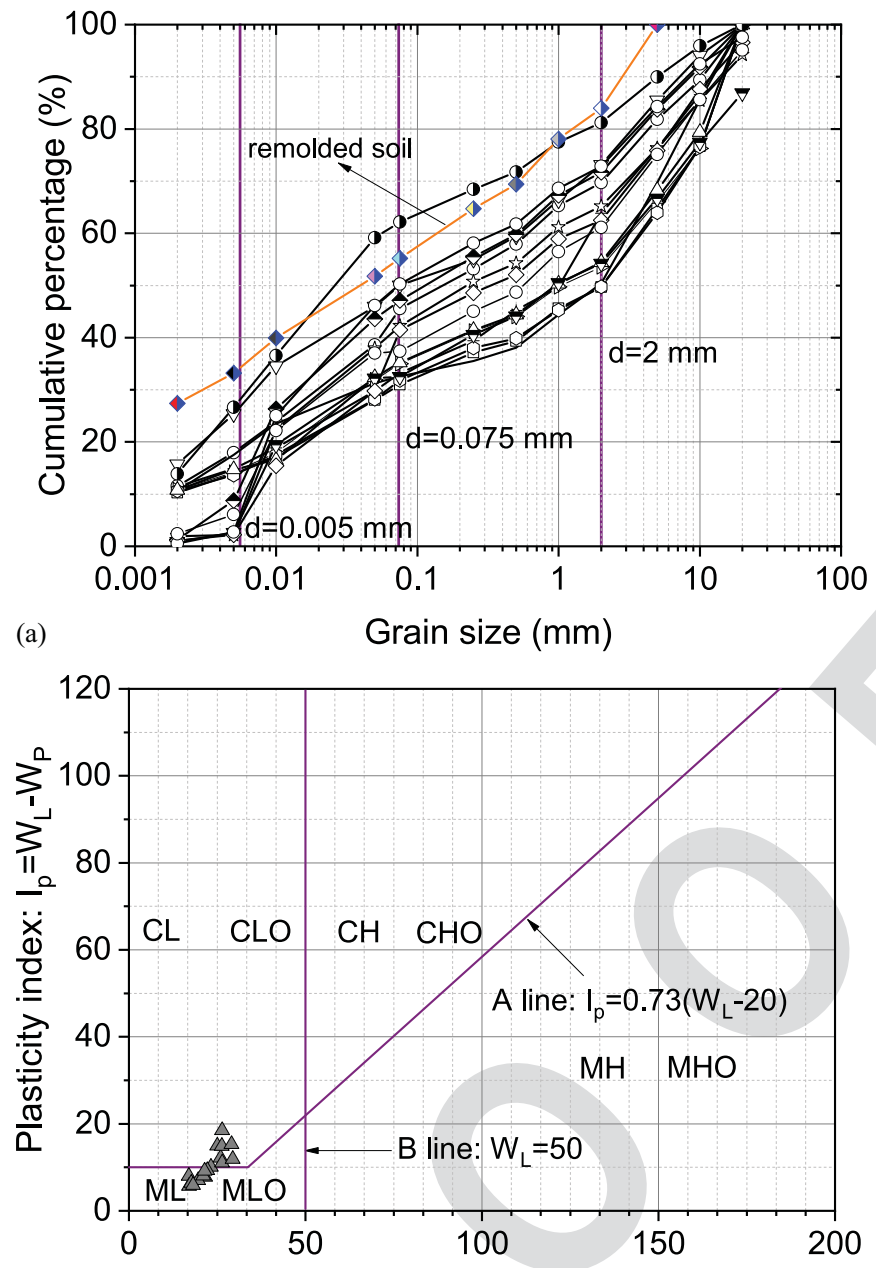

(b)

Liquid limit: $\mathrm{W}_{\mathrm{L}}(\%)$
$\mathrm{F} 2: 1$

$\mathrm{F} 2: 2$

$\mathrm{F} 2: 3$
Fig. 2. (a) Grain size distribution of intact and remoulded soils; and (b) plasticity of remoulded soil without coarse particles. (Data from Wang et al. 2020.) landslide usually give rise to very scattered results (Wang et al. 2018b; Li et al. 2017; Tan et al. 2018; Wang et al. 2020). To highlight the loading-relaxation coupling effects, therefore, remoulded soil with a particle size less than $5 \mathrm{~mm}$ was used in this study. Cylindrical specimens of $50 \mathrm{~mm}$ diameter were prepared with equal heights of $100 \mathrm{~mm}$ for the tests. The ratio of the specimen diameter to the maximum particle size is 10 , which satisfies the requirement for minimizing the boundary effect. The remoulded soil was mixed with water to reach a natural water content and, then, the material was stored in a covered container for 2 days. To achieve better homogeneity, the specimens were compacted into six layers using a split mould with a circular cross-section to achieve the desired bulk density of $2.25 \mathrm{~g} / \mathrm{cm}^{3}$ and an initial void ratio of $e_{i}=0.49$. During specimen preparation, the specimens were vacuumed for $12 \mathrm{~h}$ before being saturated with deaired water. $B$-value checks were performed before the triaxial tests, and values of 0.95 or greater were obtained, indicating high degrees of saturation of the specimens.

\section{Test Plan}

Two types of tests were performed: conventional consolidated drained triaxial (CD test, including an unloading-reloading test, i.e., UR test), and combined loading-relaxation tests (LR tests). The program for all involved tests is given in Table 1 . The experimental work was performed on a triaxial testing system from GDS Instruments. Prior to the LR tests, the CD and UR tests were carried out to determine the stress-strain relationships of shear zone soil under the drained triaxial compression condition. The CD and UR tests were strain rate controlled with a constant strain rate of $\dot{\varepsilon}_{a}=0.0002 / \mathrm{min}$ during loading. The confining pressure of the UR and CD2 tests was set to be $1,000 \mathrm{kPa}$ with a constant pore water pressure of $300 \mathrm{kPa}$, thereby providing an effective confining pressure of $700 \mathrm{kPa}$. This confining pressure and pore pressure were calculated according to the burial depth of the shear-zone soil and underground water level in the sliding masses. An additional three $\mathrm{CD}$ tests $(\mathrm{CD} 1, \mathrm{CD} 3$, and CD4) with effective confining pressures of $400,1,000$, and $1,300 \mathrm{kPa}$ were performed for comparison.

The LR tests were carried to investigate the loading-relaxation effects that occurred in the shear zone. The soil in the shear zone may experience a stress relaxation after loading with different rates of displacement, loading time, and loading interval. The effects of these factors on the loading-relaxation behavior of the shear zone soil can be evaluated using a single specimen in the LR test (Sheahan et al. 1994). An axial strain-controlled approach was employed during the relaxation tests, in which the axial strain was kept constant when the desired strain was reached, but the radial strains were free to evolve during the testing process. This boundary condition is consistent with that of the soil in the shear zone.

Four LR tests, namely, LR1, LR2, LR3, and LR4, were performed under the same confining pressure as the CD2 test.

Table 1. Test program of all tests on sliding zone soil

$\mathrm{T} 1: 1$

$\mathrm{T} 1: 2$

$\mathrm{T} 1: 3$

$\mathrm{T} 1: 4$

$\mathrm{T} 1: 5$

$\mathrm{T} 1: 6$

$\mathrm{T} 1: 7$

$\mathrm{T} 1: 8$

$\mathrm{T} 1: 9$

$\mathrm{T} 1: 10$

$\mathrm{T} 1: 11$

\begin{tabular}{lcccccc}
\hline Test name & $\begin{array}{c}\sigma_{3} \\
(\mathrm{kPa})\end{array}$ & $\begin{array}{c}u \\
(\mathrm{kPa})\end{array}$ & $\begin{array}{c}\sigma_{3}^{\prime} \\
(\mathrm{kPa})\end{array}$ & $\begin{array}{c}\text { Relaxation strain } \\
\varepsilon_{a}(\%)\end{array}$ & $\begin{array}{c}\text { Strain rates } \\
\left(/ \mathrm{min} \times 10^{-2}\right)\end{array}$ \\
\hline CD1 & 700 & 300 & 400 & - & 0.02 \\
CD2 & 1,000 & 300 & 700 & - & 0.02 \\
CD3 & 1,300 & 300 & 1,000 & - & 0.02 \\
CD4 & 1,600 & 300 & 1,300 & - & 0.02 \\
UR & 1,000 & 300 & 700 & $3,6,9,12,15,18,21$ & 0.02 \\
LR1 & 1,000 & 300 & 700 & $3,6,9,12,15,18$ & 0.02 \\
LR2 & 1,000 & 300 & 700 & $3,3,12,15,17,18$ & $0.02-1.0$ \\
LR3 & 1,000 & 300 & 700 & $3,6,9,12$ & 0.02 \\
LR4 & 1,000 & 300 & 700 & & 24 \\
\hline
\end{tabular}



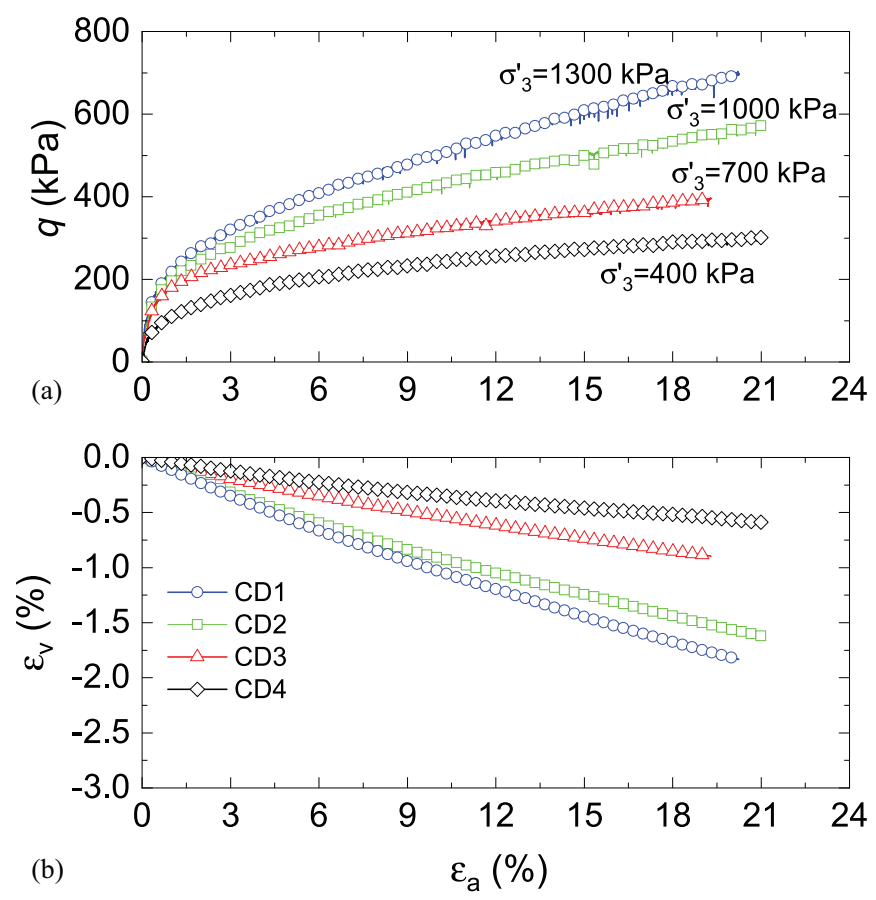

F3:1 3 Fig. 3. Deviatoric stress $(q)$ and volumetric strain $\left(\varepsilon_{v}\right)$ against axial F3:2 strain $\left(\varepsilon_{a}\right)$ for $\mathrm{CD}$ tests.

The LR1 test can be regarded as a reference test, which is hereafter referred to as the regular relaxation test. The strain rates of the LR1 tests were $\dot{\varepsilon}_{a}=0.0002 / \mathrm{min}$, and relaxation duration was 1 day for each relaxation process. The axial strain level increments between two adjacent relaxation tests were 3\%. On the other hand, the effects of loading rate, relaxation time, and prestrain interval on the reloading characteristics of shear zone soil were explored through LR2, LR3, and LR4 tests, respectively. Compared with the LR1 test, the conditions for the stress relaxation are variable in the LR2, LR3, and LR4 tests. Therefore, the term irregular relaxation test is used to refer to these tests. Specifically, the LR2 test was designed for investigating the effects of strain rate at the loading process on the reloading response of shear zone soil. In the LR3 test, multistage stress-relaxation tests were carried out with different strain increments. The LR4 test was performed to study the relaxation time on the mechanical response of shear zone soil. To this end, the relaxation duration was extended from 1 to 3 days.

\section{Experimental Results}

\section{Conventional and Unloading-Reloading Tests}

The stress-strain results of the CD and UR tests are shown in Figs. 3 and 4, respectively. In general, all specimens exhibit strain hardening behavior during shearing in the $\mathrm{CD}$ tests. The volumetric strain increases with the increase in the confining pressures. The critical state is not achieved in all CD tests. This may be attributed to the situation of the remoulded shear-zone soil being normally consolidated. In the initial state, the soil in the shear zone of the Huangtupo landslide is heavily consolidated; thus, the critical state can be easily achieved in the intact samples under the triaxial compression loading condition ( $\mathrm{Li}$ et al. 2017). In the UR test, both the unloading and reloading curves exhibit obvious nonlinearity. With an increase in the axial strain, the hysteresis loops caused by the unloading-reloading cycles change only in size whereas the shapes
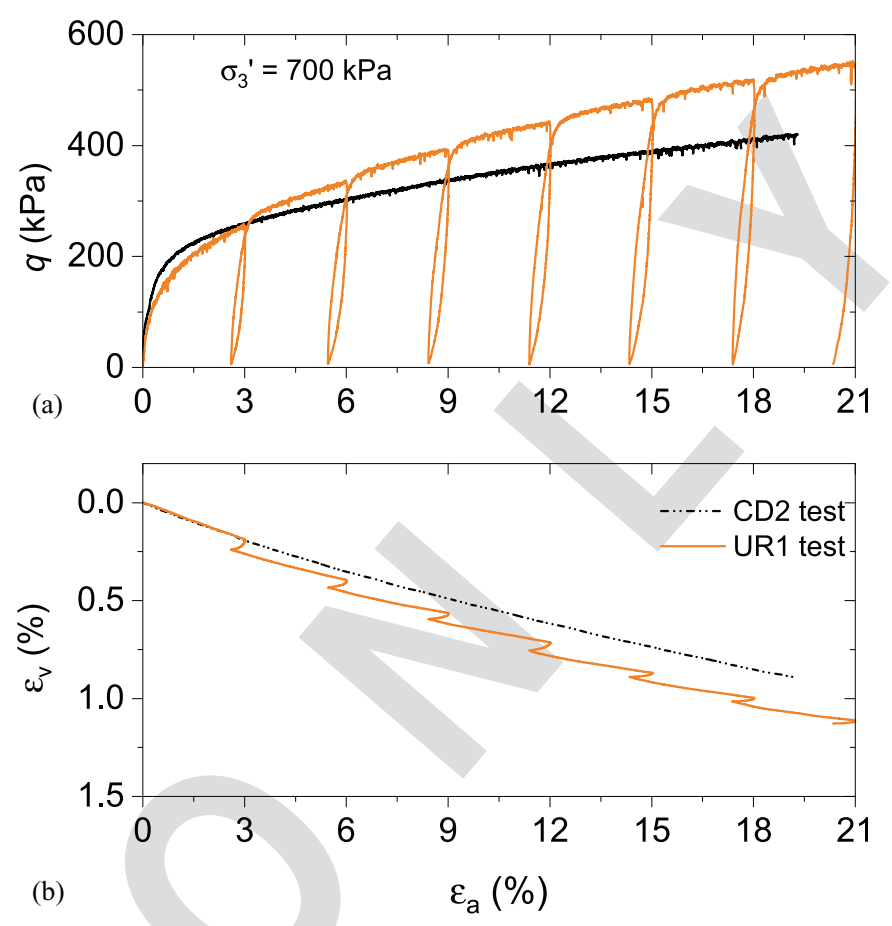

Fig. 4. Deviatoric stress $(q)$ and volumetric strain $\left(\varepsilon_{v}\right)$ against axial strain $\left(\varepsilon_{a}\right)$ for the UR test.

remain unchanged. Compared with the CD2 test, a noteworthy enhancement in the strength is observed after each unloadingreloading cycle. This strengthening behavior is most likely due to the drainage process that occurred during the unloading-reloading cycles. As shown in Fig. 4(b), contractive volume changes are observed during the unloading-reloading cycle, leading to a larger volumetric strain in the UR specimen. This observation indicates that more pore water was drained from the UR specimen.

\section{Regular Relaxation Test}

Fig. 5(a) shows the results of the LR1 test compared with the CD2 test. The deviatoric stress shows a monotonic increase to the ultimate state plateau. There were seven stress-relaxation and reloading steps involved in the LR1 test. It is worth noting that a switch of the stress evolution from strain hardening to strain softening at a certain strain level was observed in the LR1 test. At each stress-relaxation stage, the deviatoric stress experienced a significant decrease to a residual value, which is smaller than that measured in the CD2 test. On the other hand, each reloading gives rise to a peak deviatoric stress that is significantly greater than that obtained from the CD2 test at the same strain level. Obviously, a hardening effect occurred during the previous relaxation process.

Fig. 5(b) presents the total volume change of the CD2 test and the LR1 test. The former shows a linear trend with axial strain, whereas the latter exhibits a multistep curve. Compared with the volume variation of the $\mathrm{CD} 2$ test, the LR1 test gave rise to a remarkable contraction during the relaxation steps rather than the loading phases. In addition, the volume change caused by loading can be extracted from the total volume strain, which is shown by the dashed line. In contrast to the volume change of the CD2 test, the presumed volume change by loading in the LR 1 test shows first contraction and then dilatancy at $\varepsilon_{a}=9 \%$, which shows an excellent agreement with the transition of stress from strain hardening to strain softening.
$\mathrm{F} 4: 1$

$\mathrm{F} 4: 2$ 

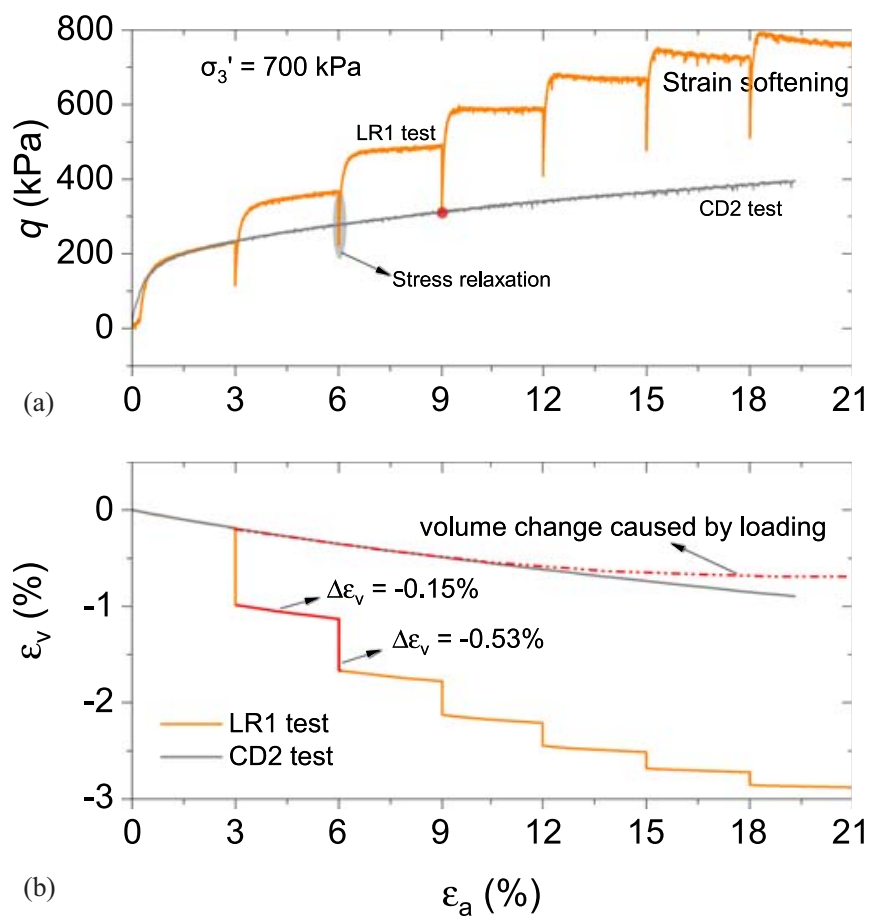

F5:1

F5:2

F5:3

Fig. 5. Comparison between the CD2 test and the LR1 test: (a) deviatoric stress versus axial strain; and (b) volumetric strain versus axial strain.

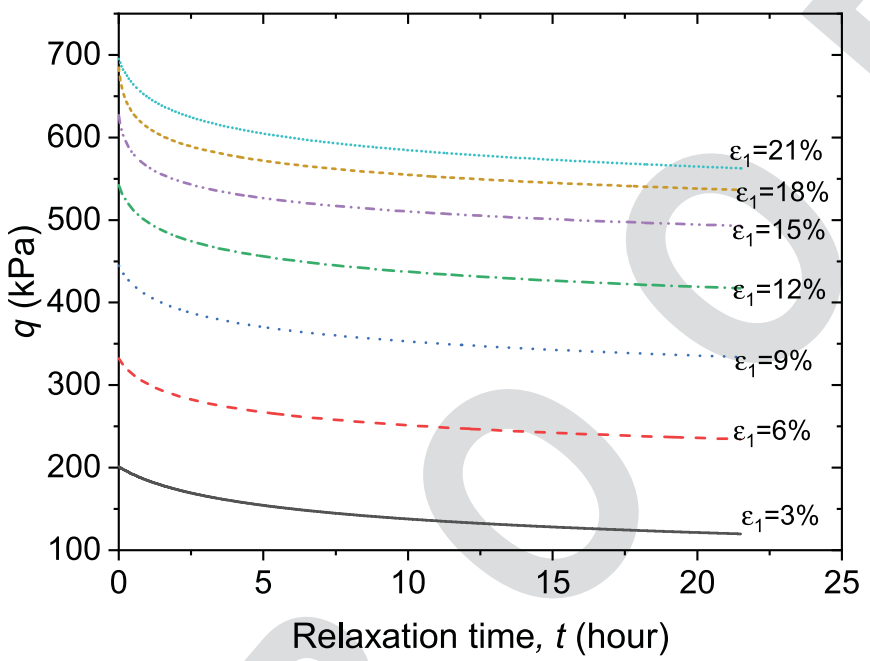

F6:1 F6:2
Fig. 6. Relaxation of deviatoric stress in the LR1 test at different strain levels. toric stress versus relaxation time. The first stress-relaxation stage occurred at a strain level of 3\% under an effective mean stress $p^{\prime}=777.6 \mathrm{kPa}$. Six subsequent relaxation tests were coupled with reloading. The results reveal that the stress rates decrease with time leading to a stabilized stress state dependent on the applied strain amplitude. Each stress-relaxation curve shows similar time-dependent characteristics, and the relative amplitude of the deviatoric stress decrease $\Delta q / q$ appear to be independent of the applied strain. This result confirms that the viscosity influence is independent of the stress and strain. Similar result was reported in the stress relaxation of saturated clay under undrained triaxial condition (Hicher 2016).
Fig. 6 shows the stress-relaxation curves in terms of devia-

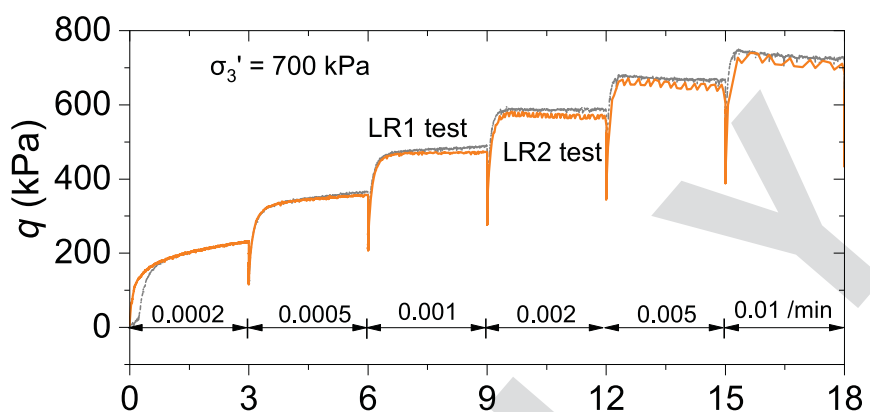

(a)

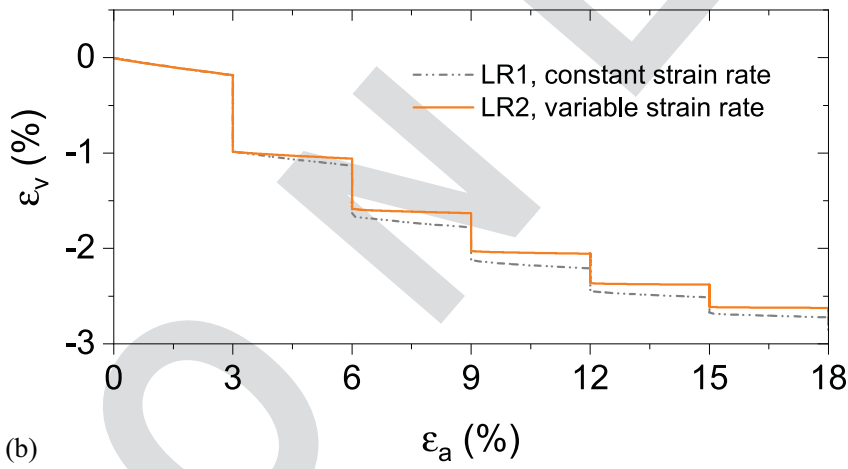

Fig. 7. Comparison between results of LR1 and LR2 tests: (a) deviatoric stress versus axial strain; and (b) volumetric strain versus axial strain.

\section{Irregular Relaxation Test}

In the following, we present the results of the irregular relaxation tests, i.e., the LR2, LR3, and LR4 tests. The effects of loading rate, loading increments, and relaxation time on the mechanical response of the combined LR tests are investigated. The results of the irregular relaxation tests are compared with the LR1 test.

\section{Dependence on Loading Rate}

Fig. 7 shows the deviatoric stress and volumetric change obtained from the LR2 test. The comparison between the LR1 and LR2 tests reveals that the deviatoric stress decreases with increasing strain rate during the reloading steps. These negative rate effects are most likely owing to the generation of pore water pressure in the specimen at high strain rates. This situation leads to a decrease in the deviatoric stress. In addition, the volumetric strain evolution of the specimen is the result of the combined effects of a change in the effective mean pressure during the relaxation process and the viscous properties of the material. A similar switch of the strain-hardening to stainsoftening characteristic is observed in the LR2 test. It is also found that the volumetric strain of each step varies with rate of strain. The volumetric strain of the LR1 test is greater than that of the LR2 test with a variable rate of strain, as shown in Fig. 7(b).

Fig. 8 shows the comparison of stress-relaxation responses obtained from the LR1 and LR2 tests. Distinct relaxation behaviors are observed in these two tests. For the LR1 test, with the same loading rate at each reloading stage, the relaxation test starting at a higher strain level will give rise to a relatively smaller stress-relaxation ratio. Compared with the LR1 test, the LR2 test obtains much smaller stress-relaxation ratios for all relaxation tests. In contrast to the LR1 test, in the LR2 test, the relaxation starting at a smaller strain level obtains a larger stress-relaxation ratio at the beginning of stress relaxation. After $5 \mathrm{~h}$, all relaxation curves intersect at a transition point. Subsequently, the LR2 test exhibits the same relaxation trends as that observed in the LR1 test. This experimental observation 


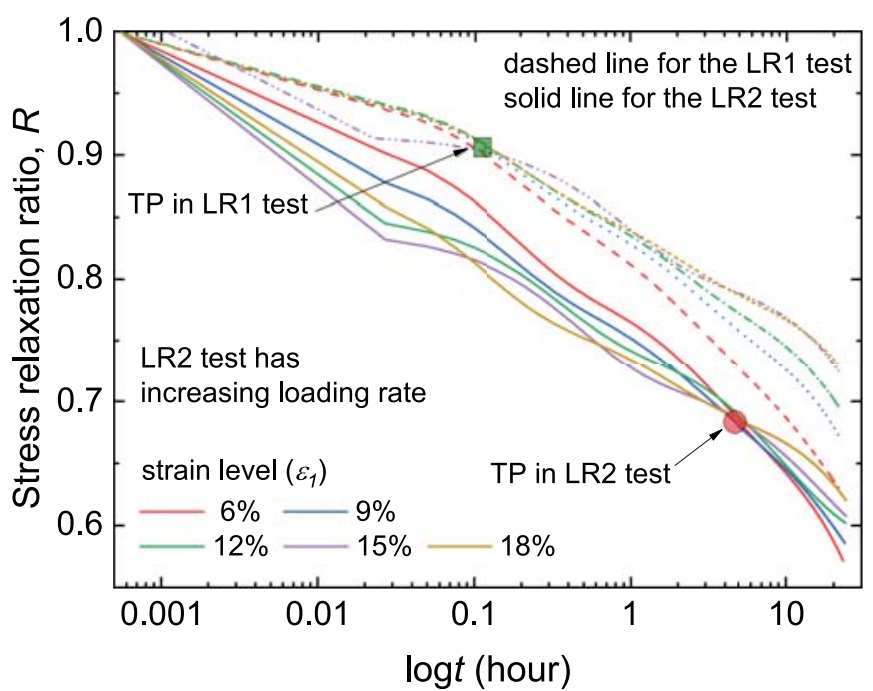

F8:1 Fig. 8. Comparison of stress-relaxation results in the LR1 and LR2 F8:2 tests (TP: transition point). indicates that the strain rate at the previous loading stage has a remarkable influence on the relaxation response. This effect, however, gradually disappears after the transition point.

\section{Effect of Loading Increment}

Fig. 9 shows the comparison of the LR1 and LR3 tests. The difference in loading increments gives rise to different mechanical responses. For example, the LR3 test yields a larger deviatoric stress at the axial strain ranging from $\varepsilon_{a}=2-9 \%$. The difference in deviatoric stress, however, is compensated at $\varepsilon_{a}=9 \%$ after the LR 1 test experiences the same number of relaxation processes as that in the LR3 test. Thereafter, the LR1 and LR3 tests gain almost the same deviatoric stress, until the LR3 test undergoes one more stress relaxation at $\varepsilon_{a}=17 \%$. Although the LR3 test experienced a larger volume change during the entire loading-relaxation process, as shown in Fig. 9(b), it is believed that the stress curve of the LR3 test will coincide with that of the LR 1 test after $\varepsilon_{a}=18 \%$. In addition, the LR3 test also shows a switch of strain hardening to strain softening in the stress-strain curve, whereas this transition point appears at $\varepsilon_{a}=12 \%$ rather than $\varepsilon_{a}=9 \%$ in the LR 1 test.

The comparison of stress relaxation responses from the LR1 and LR2 tests is presented in Fig. 10. A similar stress-relaxation behavior is observed in these two tests. Likewise, the transition point appears at approximately $3 \mathrm{~min}$, earlier than that observed in the LR1 test, after the relaxation test starts. Compared with the LR1 test, the LR3 test experienced one more relaxation process at the earlier stage of axial strain. This additional process gives rise to a strengthening effect to the soil. As a result, at the same strain level, the stress-relaxation ratios in the LR3 test are larger than those measured in the LR1 test.

\section{Effect of Relaxation Time}

Previous investigation has shown that neither test LR2 nor test LR3 exhibited an obvious third stage of stress relaxation. This is because the stress was relaxed for only 1 day in both tests. Thereafter, in the LR4 test, the duration of the stress-relaxation stage was extended to 3 days, whereas the other conditions were kept the same as in the LR1 test.

The coupling effects of relaxation time on the mechanical behavior of shear-zone soil during reloading are shown in Fig. 11. In comparison with the LR1 test with 1-day relaxation duration, the time effect is more pronounced in the LR4 test with 3-day relaxation. As shown in Fig. 11(a), the reloading gains much higher deviatoric
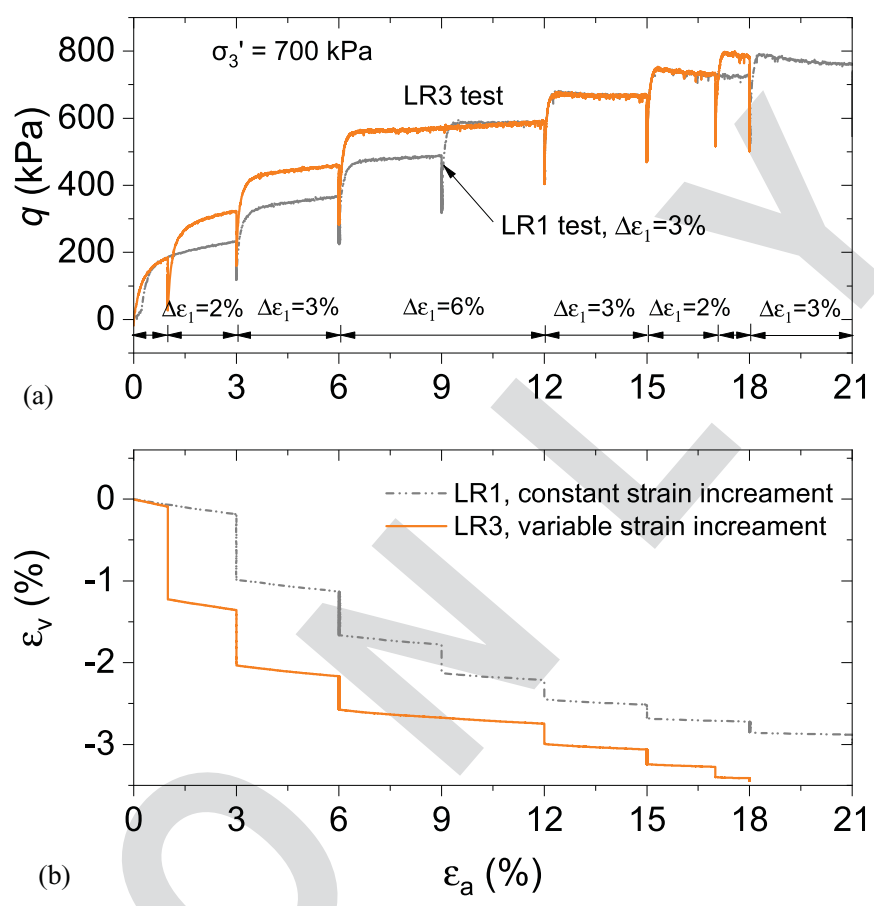

Fig. 9. Comparison between results of LR1 and LR3 tests: (a) deviatoric stress versus axial strain; and (b) volumetric strain versus axial strain.

F9:1

F9:2

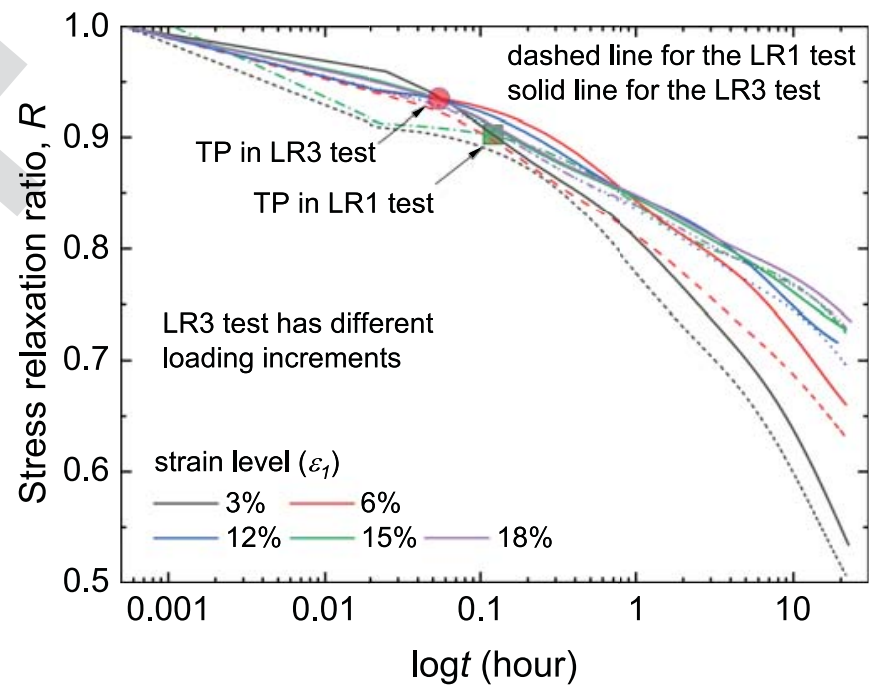

Fig. 10. Comparison of stress-relaxation results in the LR1 and LR3 tests (TP: transition point).

stress under the strain level of $6 \%$. For the subsequent reloading at higher strain levels, the difference due to the longer previous relaxation duration becomes more visible. It is interesting to note that the deviatoric stress $q_{1}$ is almost equal to $q_{2}$, with $q_{1}$ and $q_{2}$ being the deviatoric stress at the beginning of the third reloading state in the LR1 test, and at the end of the first reloading state in the LR4 test, respectively. Fig. 11(b) presents the volume change of the LR1 and LR2 tests. Clearly, the LR4 test gained much greater volume contraction than that in the LR1 test during the entire relaxation duration. Nevertheless, for the loading process, the LR1 test obtained a slightly larger volume contraction, as shown by the dashed line in Fig. 11(b).

Fig. 12 shows the comparison of stress-relaxation responses from the LR1 and LR4 tests. A similar trend of stress relaxation is observed in the LR1 and the LR4 tests, with the former giving
F10:1

F10:2

330

331

332

333

334

335

336

337

338

339

340

341

342

343 

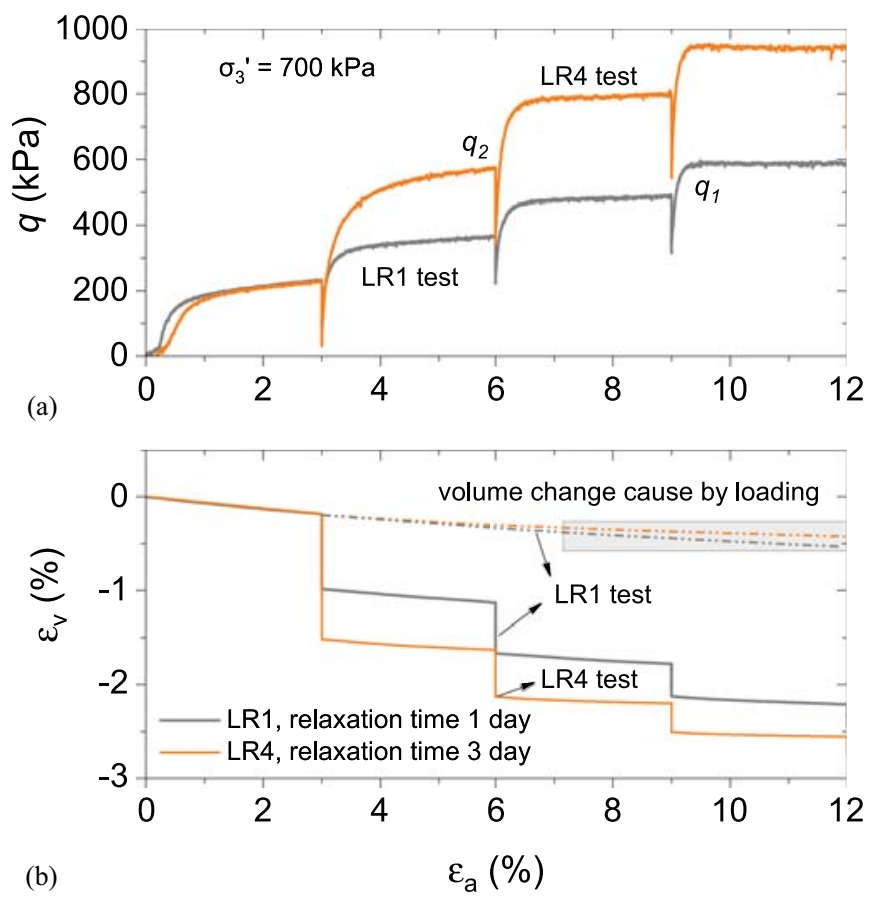

Fig. 11. Comparison between the results of LR1 and LR4 tests with 1and 3-day relaxation duration, respectively: (a) deviatoric stress versus axial strain; and (b) volumetric strain versus axial strain.

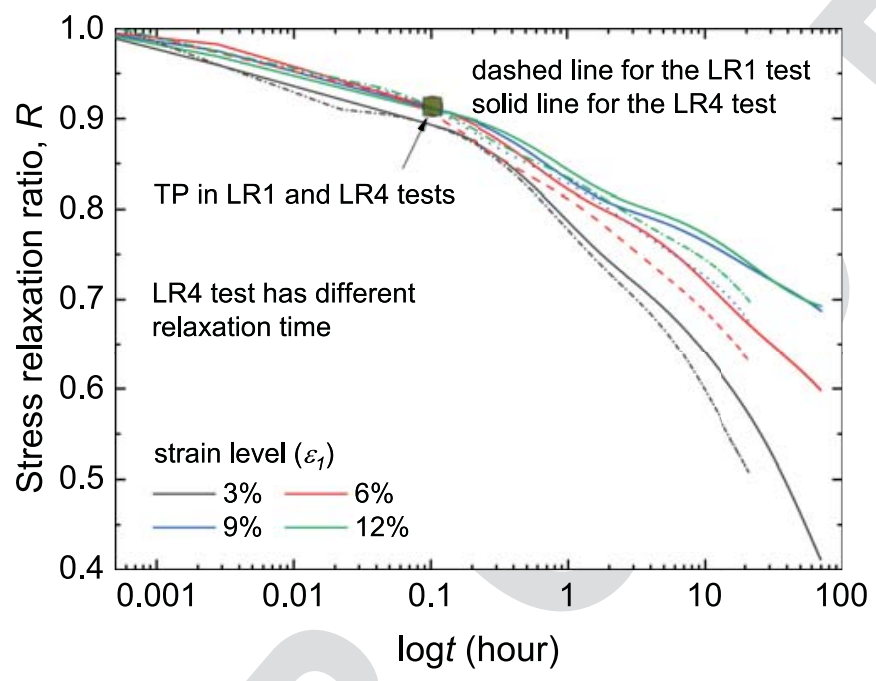

F12:1

F12:2
Fig. 12. Comparison of stress-relaxation results in the LR1 and LR4 tests (TP: transition point).

rise to larger stress-relaxation ratios. This is attributed to the strengthening effect caused by the relaxation process. In contrast to the LR2 and LR3 tests, the transition point in the LR4 tests coincides with that observed in the LR1 test. Although a longer relaxation duration gives rise to a large initial stress for the next stage of stress relaxation, the previous relaxation time may not significantly influence the initial response of the subsequent stress relaxation.

\section{Mechanical Theory}

From the test results presented in the previous section, it is found that (i) the mechanical behaviors under reloading are influenced

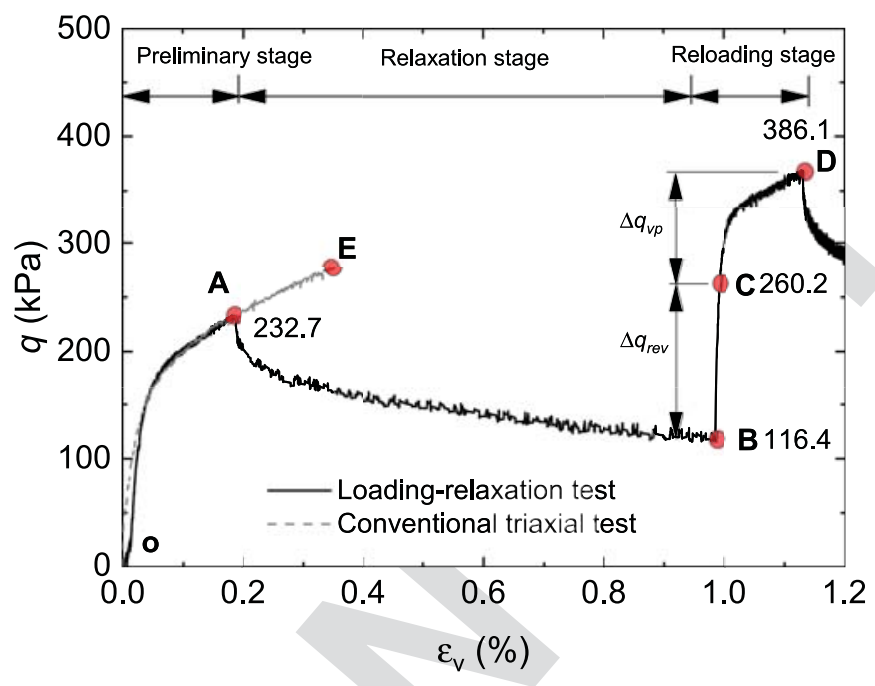

Fig. 13. Typical stages of the combined loading-relaxation test (data from CD2 and LR1 tests).

by previous relaxation processes, and (ii) stress-relaxation behavior is independent of the stress and strain levels, but can be influenced by preceding loading patterns and relaxation history. In the following, the loading-relaxation coupling effects are discussed through two aspects: the viscoplastic hardening effect and the effect of the preceding loading pattern.

\section{Viscoplastic Hardening Effect}

The whole process of a loading-relaxation test is illustrated in Fig. 13, in which a loading-relaxation curve can be divided into three stages, namely, a preliminary stage (line $O A$ ), a relaxation stage (line $A B$ ), and a reloading stage (line $B C D$ ). The stress-strain curve of the preliminary stage maintains the same behavior as that in a conventional triaxial compression test, as shown by the curve $O A E$. In the relaxation stage, the deviatoric stress relaxes with time. Although the axial strain remains unchanged, the volumetric strain still increases owing to the radial strain. Therefore, the radial strain presents the whole volume change, and it is obviously larger than that caused in the preliminary stage.

The viscoplastic hardening can be clearly observed in the reloading stage (line $B C D$ ), which leads to a significant strengthening in the deviatoric stress in comparison with the loading of in the conventional triaxial test (line $O E$ ). The stress-strain response in this stage can be further divided into two parts: the viscoelastic loading (line $B C$ ) and the viscoplastic loading (line $C D$ ), which give rise to deviatoric stress increments $\Delta q_{\mathrm{rev}}$ and $\Delta q_{\mathrm{vp}}$, respectively. In the viscoelastic loading part, the tangent stiffness (slope of line $B C$ ) is significantly greater than that in the conventional triaxial tests. Beyond point $C$, the influence of relaxation on the stress-strain response begins to weaken. The trend of the stressstrain curve (line $C D$ ) becomes identical to that in the conventional triaxial compression test (line $A E$ ).

The reason for the aforementioned viscoplastic hardening might be attributed to structure adjustment, particle rearrangement, and drainage under confining pressure during the stress-relaxation stage. The viscoplastic hardening can be explained on the basis of the elastoviscoplastic theory. It is assumed that the strain increment tensor can be decomposed into an elastic and a viscoplastic components:

$$
d \boldsymbol{\varepsilon}=d \boldsymbol{\varepsilon}^{\mathrm{rev}}+d \boldsymbol{\varepsilon}^{\mathrm{vp}}
$$

F13:1

F13:2

354 

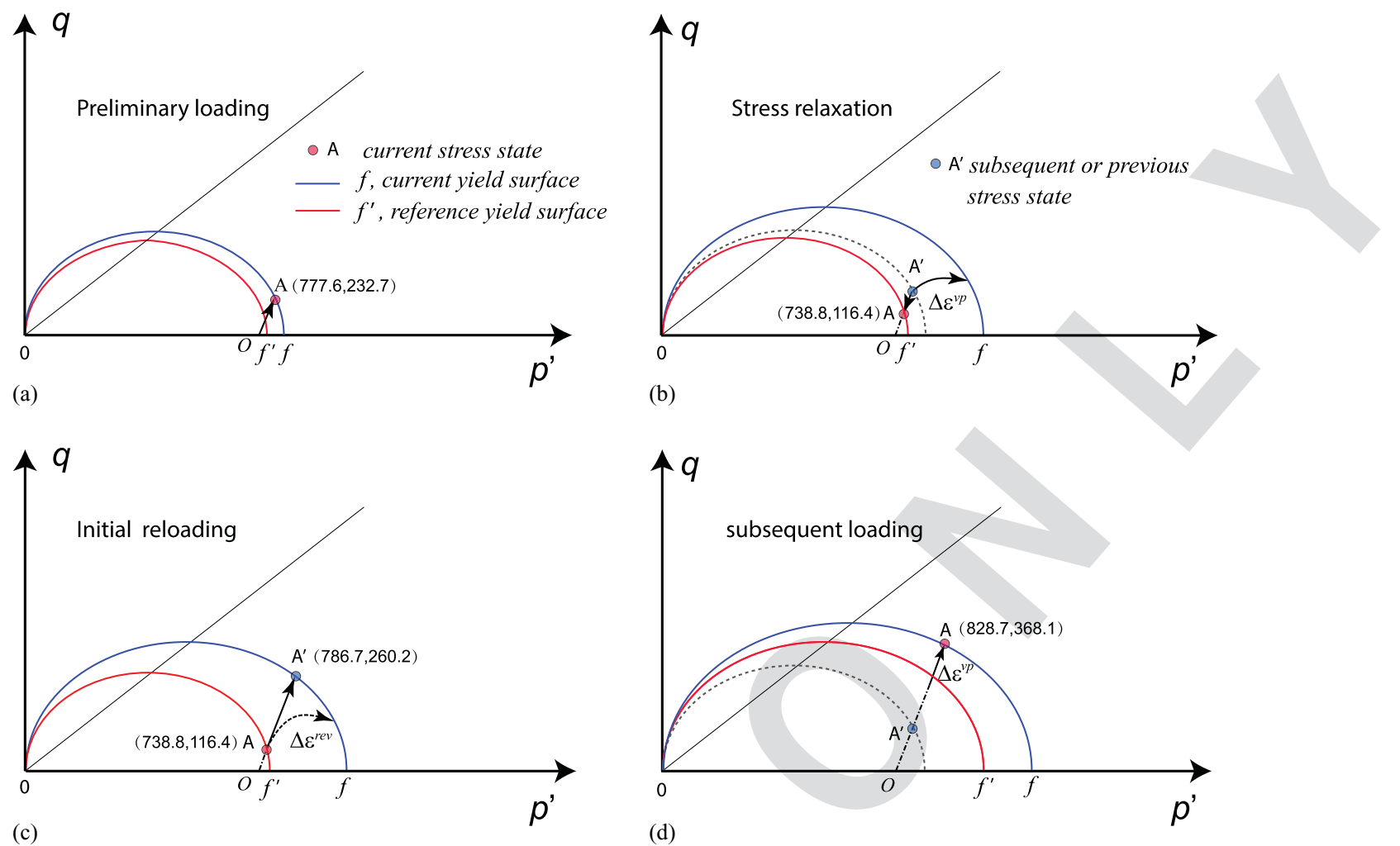

(d)

F14:1 Fig. 14. Illustration of viscoplastic hardening (units: kPa): (a) preliminary loading; (b) stress relaxation; (c) initial reloading; and (d) subsequent loading. The stress states are obtained from the LR1 test with $\varepsilon_{a}=3 \%-6 \%$.

where $d \boldsymbol{\varepsilon}^{\mathrm{rev}}$ and $d \boldsymbol{\varepsilon}^{\mathrm{vp}}$ denote the viscoelastic and the viscoplastic strain increment tensors, respectively. To interpret the viscoplastic hardening effect, we assume a time-dependent current yield surface $f$ and a reference surface $f$ that are mobilized during the loading phase, such as proposed by Yao et al. (2015). When the stress goes beyond the current yield surface $f$, the viscoplastic strain is created. Meanwhile, hardening will develop and the current yield surface will evolve according to hardening function. The viscoplastic increment tensor is determined by

$$
d \boldsymbol{\varepsilon}^{\mathrm{vp}}=\Phi \frac{\partial g}{\partial \boldsymbol{\sigma}}
$$

where $\Phi$ is the viscoplastic scalar multiplier, which is dependent on the stress increment, the distance between the current stress point, and the reference stress point and real-time increment (Yao et al. 2015). The direction of the viscoplastic strain is dictated by the potential $g$. The interpretation of the viscoplastic hardening effect is shown in Fig. 14. The stress states are obtained from the LR 1 test with $\varepsilon_{a}=3 \%-6 \%$. The viscoplastic hardening effect is explained as follows:

(a) In the preliminary stage, the material undergoes viscoplastic strain if the stress state goes beyond the current yield surface $f$; thus, both the reference surface and the current yield surface expand accordingly because of the accumulation of viscoplastic strain.

(b) During relaxation, the stress state is located outside the reference yield surface $f$. Owing to the distance between the current and the reference surfaces, the stress relaxes until the stress state moves back to the reference yield surface $\left(A^{\prime} \rightarrow A\right)$, but the current yield surface $f$ is further pushed and expanded owing to the viscoplastic strain increment $\Delta \epsilon_{\mathrm{vp}}$.

(c) In the reloading stage, the load is applied following the same stress path as that in the preliminary stage. During the initial viscoelastic loading $\left(A \rightarrow A^{\prime}\right)$, the stress state moves from $A$ to $A^{\prime}$. Because $A A^{\prime}$ is inside the current yield surface $f$, the loading strain $\Delta \epsilon_{\text {rev }}$ is reversible.

(d) With further loading, the stress state moves back the limit yield surface $f$. Viscoplastic strain increment $\Delta \epsilon_{\mathrm{vp}}$ will be produced again. Consequently, both the reference surface $f^{\prime}$ and the current yield surface $f$ expand forward. The current stress state is located outside the reference surface, and stress relaxation is bound to occur owing to the over-stress.

According to the above discussion, it is evident that the relaxation stage indeed has a significant effect on the mechanical response in the reloading. In addition, the viscoplastic hardening is time dependent, that is, a longer relaxation stage would give rise to a larger increase in the deviatoric stress in the subsequent reloading stage (see test LR3). Moreover, the viscoplastic hardening is independent of the strain level (see test LR4). This result is also confirmed by Hicher (2016) in stress-relaxation test under undrained condition. Apparently, the viscoplastic hardening is a result of the increase in the radial strain during a relaxation stage. As the specimen had not reached a vanishing value in radial strain, the radial strain may transform into another time-dependent process, i.e., creep, owing to the confining pressure. In fact, the mechanisms that take place during stress relaxation that lead to displacements and strains are fairly complicated.

\section{Effect of Preceding Loading Pattern}

Two indexes, the stress-relaxation ratio $R$ and the initial relaxation velocity $v_{\mathrm{ri}}$, are adopted to evaluate the effects of preceding loading patterns on the relaxation behavior. The stress-relaxation ratio $R$ is defined as the ratio of the deviatoric stress at any time, $q_{r}(t)$, to the stress at the beginning of the stress relaxation, $q_{i}$ (e.g., Yin and Graham 1989; Yin et al. 2014; Hicher 2016): 

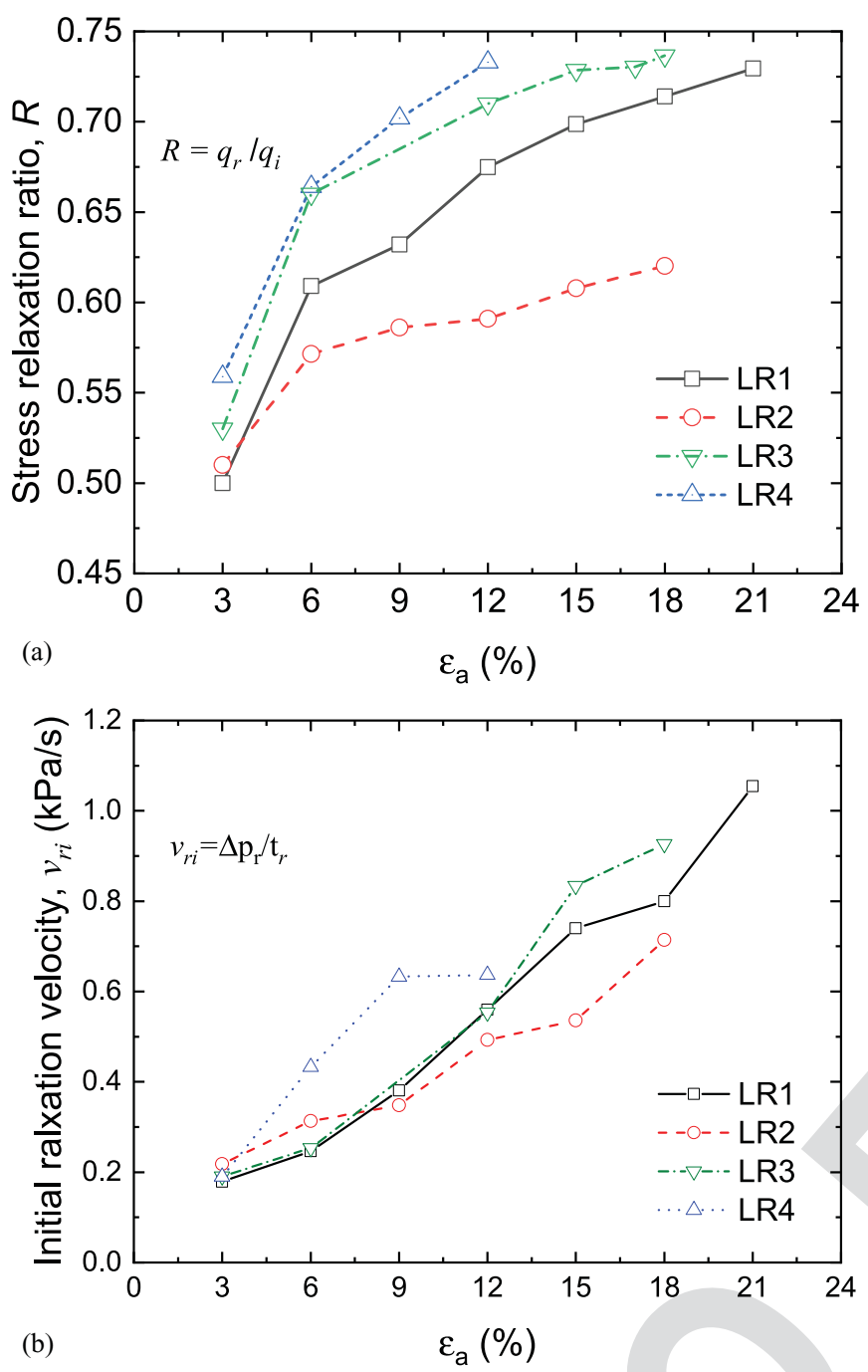

F15:1

Fig. 15. (a) Relaxation ratio $R$ after $24 \mathrm{~h}$ stress relaxation; and (b) initial relaxation rate $v_{\text {ri }}$ after $60 \mathrm{~s}$ stress relaxation.

$$
R(t)=\frac{q_{r}(t)}{q_{i}}
$$
axial strain. For example, for the LR1 test, the ratio $R$ increases from 0.5 to 0.7 as the axial strain increases from $3 \%$ to $15 \%$, respectively, and then remains unchanged despite further increase in the axial strain. The influence of the loading rate on the relaxation behavior becomes larger with increasing axial strain. For instance, with an increase in the preceding loading rate from $0.0005 / \mathrm{min}$ at $\varepsilon_{a}=9 \%$ to $0.005 / \mathrm{min}$ at $\varepsilon_{a}=15 \%$, the difference in $R$ between the LR1 and LR2 tests enlarged from 0.03 to 0.11 , respectively. The stressrelaxation ratio $R$, however, suggests that an increase in relaxation time results in a lower relative stress reduction during the relaxation

\section{Conclusions} toviscoplastic theory, provided the viscoplastic strain con- stages. The results suggest that stress relaxation may significantly influence the reloading behavior through relaxation time.

As shown in Fig. 15(b), the initial relaxation velocity defined in Eq. (4) increases with increasing axial strain in all tests, with the LR4 and LR2 tests giving rise to the highest and the lowest values, respectively. The LR4 specimen experiences much longer relaxation duration with an accumulation of viscoplastic hardening in the soil. The specimen, therefore, exhibits more elastic behavior among the four specimens. In contrast, the LR2 specimen is sheared with an increasing strain rate. The shearing with a high strain rate to some extent spoils the microstructure of the specimen and, thus, leads to a weakened effect on the viscoelastic response of the soil.

In this paper, we report on the loading-relaxation coupling effect of reconstituted shear-zone soil of a slow-moving landslide by performing a series of drained triaxial tests. A strong loading-relaxation coupling effect is observed in the experiments, and the following conclusions can be drawn:

(1) A reloading after a stress-relaxation process gives rise to a higher deviatoric stress owing to the viscoplastic hardening effect. The viscoplastic hardening effect is time dependent, that is, a long-term relaxation process achieves the similar hardening effect as several cumulative short-term relaxation processes. In addition, the behavior upon reloading after relaxation is initially in an viscoelastic regime, which can be enhanced by increasing the relaxation time.

(2) The preceding loading patterns affect mainly the viscoelastic behavior of the soil, and subsequently influence the initial relaxation behavior. The loading increments and relaxation duration influence the subsequent relaxation behavior through the viscoplastic hardening effects. In terms of the relaxation duration, we found that longer previous relaxation leads to observable differences in the initial drop of the stress as well as the relative stress reduction.

(3) The loading-relaxation coupling can be interpreted with elastribute to the expansion of the current yield surface. This relaxation-induced strain is largely dependent on the radial strain during the relaxation process.

It should be noting that different landslide processes may lead to various shear zones and the soil within the shear zones are usually inherently inhomogeneous in coarse particles and macrostructures. These features may influence the viscous behaviors of the shearzone soils. Moreover, the soils may experience more complex stress and strain paths, e.g., creep along with stress relaxation, under the in situ conditions. Therefore, our conclusions are limited to the reconstituted shear-zone soil of the Huangtupo landslide. To develop a general constitutive model for such soils, further experimental investigations on the viscous behavior of intact shear-zone soils under complex loading conditions are required.

\section{Data Availability Statement}

The data for the triaxial compression behavior of the soil is available in figshare with the identifier https://doi.org/10.6084/m9.figshare . 13077632 .

\section{Acknowledgments}

Open access funding provided by the University of Natural 
funded by the National Natural Science Foundation of China (Grant Nos. 41772304 and 41602313); the H2020 Marie Skłodowska-Curie Actions RISE 2017 HERCULES (778360) and FRAMED (734485), and the Erasmus+KA2 project Re-built (2018-1-RO01-KA203-049214). The corresponding author wishes to thank the Otto Pregl Foundation for financial support in Austria.

\section{References}

Augustesen, A., M. Liingaard, and P. V. Lade. 2004. "Evaluation of timedependent behavior of soils.” Int. J. Geomech. 4 (3): 137-156. https:// doi.org/10.1061/(ASCE)1532-3641(2004)4:3(137).

Bagheri, M., M. Rezania, and N. M. Mousavi. 2019. "Rate dependency and stress relaxation of unsaturated Clays." Int. J. Geomech. 19 (12): 04019128. https://doi.org/10.1061/(ASCE)GM.1943-5622 .0001507 .

Deng, J. L., Q. Xu, and J. Koseki. 2016. "How the toe loading suppresses the movements of an instable slope: Mechanisms revealed from triaxial compression tests under varied strain rate condition." Eng. Geol. 209 (6): 93-105. https://doi.org/10.1016/j.enggeo.2016.05.012.

Deng, Q. L., Z. Y. Zhu, Z. Q. Cui, and X. P. Wang. 2000. "Mass rock creep and landsliding on the Huangtupo slope in the reservoir area of the Three Gorges Project, Yangtze River, China.” Eng. Geol. 58 (1): 67-83. https://doi.org/10.1016/S0013-7952(00)00053-3.

Feda, J. 1992. Creep of soils and related phenomena. Vol. 68 of Elsevier. Hicher, P. 2016. "Experimental study of viscoplastic mechanisms in clay under complex loading." Géotechnique 66 (8): 661-669. https://doi .org/10.1680/jgeot.15.P.203.

Hu, W., G. Scaringi, Q. Xu, Th. W. J. Van Asch, R. Q. Huang, and W. X. Han. 2018. "Suction and rate-dependent behaviour of a shear-zone soil from a landslide in a gently-inclined mudstone-sandstone sequence in the Sichuan basin, China." Eng. Geol. 237 (10): 1-11. https://doi.org /10.1016/j.enggeo.2018.02.005.

Li, C., H. M. Tang, D. W. Han, and Z. X. Zou. 2017. "Exploration of the creep properties of undisturbed shear zone soil of the Huangtupo landslide.” Bull. Eng. Geol. Environ. 78 (2): 1237-1248. https://doi.org/10 .1007/s10064-017-1174-5

Liingaard, M., A. Augustesen, and P. V. Lade. 2004. "Characterization of models for time-dependent behaviour of soils." Int. J. Geomech. 4 (3): 157-177. https://doi.org/10.1061/(ASCE)1532-3641(2004)4:3(157).

Miao, H. B., G. H. Wang, K. L. Yin, T. Kamai, and Y. Y. Li. 2014. "Mechanism of the slow-moving landslides in Jurassic red-strata in the Three Gorges Reservoir, China." Eng. Geol. 171: 59-69. https:// doi.org/10.1016/j.enggeo.2013.12.017.

Scaringi, G., W. Hu, Q. Xu, and R. Q. Huang. 2017. "Shear-rate-dependent behavior of clayey bimaterial interfaces at landslide stress levels." Geophys. Res. Lett. 45 (2): 766-777. https://doi.org/10.1002/grl.v45.2.

Sheahan, T. C., C. C. Ladd, and J. T. Germaine. 1994. "Time-dependent triaxial relaxation behavior of a resedimented clay." Geotech. Test. J. 17 (4): 444-452. https://doi.org/10.1520/GTJ10305J.

Tan, Q. W., H. M. Tang, L. Fan, C. R. Xiong, Z. Q Fan, M. Zhao, C. Li, D. J. Wang, and Z. X. Zou. 2018. "In-situ triaxial creep test for investigating deformational properties of gravelly sliding zone soil: Example of the Huangtupo $1^{\#}$ landslide, China." Landslides 15 (12): 2499-2508. https://doi.org/10.1007/s10346-018-1062-5.

Tang, H. M., J. Wasowskib, and H. Juang. 2019. "Geohazards in the three Gorges Reservoir area, China - Lessons learned from decades of research.” Eng. Geol. 261 (11): 105267. https://doi.org/10.1016/j.enggeo 2019.105267.

Troncone, A., E. Conte, and A. Donato. 2014. "Two and three-dimensional numerical analysis of the progressive failure that occurred in an excavation-induced landslide." Eng. Geol. 183 (9): 265-275. https:// doi.org/10.1016/j.enggeo.2014.08.027.

Wang, J. E., A. J. Su, Q. B. Liu, W. Xiang, H. F. Yeh, C. R. Xiong, Z. X. Zou, C. Zhong, J. Q. Liu, and S. Cao. 2018a. "Three-dimensional analyses of the shear surface distribution in the Huangtupo No. 1 riverside sliding mass in the Three Gorges Reservoir area of China." Landslides 15 (7): 1425-1435. https://doi.org/10.1007/s10346-018-1003-3.

Wang, J. E., A. J. Su, W. Xiang, H. F. Yeh, C. R. Xiong, Z. X. Zou, C. Zhong, and Q. B. Liu. 2016. "New data and interpretations of the shallow and deep deformation of Huangtupo No. 1 riverside sliding mass during seasonal rainfall and water level fluctuation." Landslides 13 (4): 795-804. https://doi.org/10.1007/s10346-016-0712-8.

Wang, S., J. E. Wang, W. Wu, D. S. Cui, A. J. Su, and W. Xiang. 2020 "Creep properties of clastic soil in a reactivated slow-moving landslide in the Three Gorges Reservoir Region, China." Eng. Geol. 267: 105493. https://doi.org/10.1016/j.enggeo.2020.105493.

Wang, S., W. Wu, J. E. Wang, Z. Y. Yin, D. S. Cui, and W. Xiang. 2018b. "Residual-state creep of clastic soil in a reactivated slow-moving landslide in the Three Gorges Reservoir Region, China." Landslides 15 (12): 2413-2422. https://doi.org/10.1007/s10346-018-1043-8.

Wang, S., W. Wu, Z. Y. Yin, C. Peng, and X. Z. He. 2018c. "Modelling the time-dependent behavior of granular material with hypoplasticity." Int. J. Numer. Anal. Methods Geomech. 42 (12): 1331-1345. https:// doi.org/10.1002/nag.v42.12.

Wang, J. E., W. Xiang, and N. Lu. 2014. "Landsliding triggered by reservoir operation: A general conceptual model with a case study at Three Gorges Reservoir." Acta Geotech. 9 (5): 771-788. https://doi.org/10 .1007/s11440-014-0315-2.

Wang, M. W., X. Y. Xu, J Li, F. J. Shen, and Y. F. Li. 2017. “An experiment study on stress relaxation of unsaturated lime-treated expansive clay." Environ. Earth Sci. 76 (6): 241. https://doi.org/10.1007/s12665 $-017-6562-4$

Wen, B. P., and X. Z. Jiang. 2017. "Effect of gravel content on creep behavior of clayey soil at residual state: Implication for its role in slowmoving landslides." Landslides 14 (2): 559-576. https://doi.org/10 .1007/s10346-016-0709-3.

Yao, Y. P., L. M. Kong, A. N. Zhou, and J. H. Yin. 2015. “Time-dependent unified hardening model: Three-dimensional elastoviscoplastic constitutive model for clays." J. Eng. Mech. 141 (6): 04014162. https://doi .org/10.1061/(ASCE)EM.1943-7889.0000885.

Yin, J. H., and J. Graham. 1989. "Viscous elastic plastic modelling of onedimensional time dependent behaviour of clays." Canad. Geotech. J. 26 (2): 199-209. https://doi.org/10.1139/t89-029.

Yin, Z. Y., Q. Y. Zhu, J. H. Yin, and Q. Ni. 2014. "Stress relaxation coefficient and formulation for soft soils." Géotech. Lett. 4 (1): 45-51. https:// doi.org/10.1680/geolett.13.00070. 